\title{
Dynamical Properties Analysis of Frictional Winding Mechanism with Bobbin Elastic Support
}

\author{
Mohammed A. Alnawafleh and Faisal M. Al-Ghathian \\ Department of Mechanical Engineering, Tafila Applied University College \\ Al-Balqa' Applied University, P.O. Box 130, Wadi Mousa, Petra, Jordan
}

\begin{abstract}
A mathematical model of the Frictional Winding Mechanism (FWM) with bobbin elastic supports for a search of optimal structural and physical parameters for developing new and updating existing FWMs has been carried out. The model was derived from bobbin equipped with pendulum suspension for forming cylinder shaped packages. In the derivation method it was considered that the model corresponds the conditions under which the contact points peripheral speeds of the package and driving drum in all the cross sections are less than the speeds of the same points belonging to the driving drum.
\end{abstract}

Key words: Frictional Winding Mechanism (FWM), Modeling, Elastic Supports of Bobbin, Drum

\section{INTRODUCTION}

One of the most widespread ways to wind up a thread onto a bobbin or a tube in textile industries is frictional way, when the rotation of a package is realized by means of the force of friction between revolving driving drums and a package pressed to it. Frictional Winding Mechanism (FWM) is well known due to the simplicity of their structure. They control the frequency of rotation of a package automatically without complementary units and reliably take a thread at the speed rate from 1000 to $1500 \mathrm{~m} \mathrm{~min}^{-1}$.

However, at higher winding up speeds the intense vibrations arise in FWM leading to unbalance of package mass. The above vibrations affect negatively the process of winding up and can give rise to a loss of a contract between a package and driving drum ${ }^{[1-3]}$.

To update FWMs, it is necessary to undertake a research over a developing of more accurate dynamical models of FWMs and computer numerical modeling of conditions of their running. Therefore, in the models should be taken into account the elastic properties of the package and its supports, statical and dynamical mis-balance of the mass of the package as well as the character of the frictional interaction of package and driving drum.

\section{MATHEMATICAL MODEL OF FWM}

Corresponding model of FWM equipped with pendulum suspension for forming a cylinder shaped package is shown in Fig. 1, where the following generalized coordinates are selected:

$\Psi$-Angular position of the lever $\mathrm{O}_{3} \mathrm{~A}$

$\mathrm{X}$-Displacement of the point $\mathrm{A}$ of the package axis along the axis $\mathrm{X}$,
$\mathrm{Z}$-Deformation of the package at the point $\mathrm{A}^{\prime}$ along the axis $Z$,

$\alpha$ And $\beta$-angular positions of the package axis relative axis $\mathrm{Z}$ and $\mathrm{X}$,

$\varphi$-Angle of package rotation.

The initial position of FWM is combined with the moment of the package touching the driving drum and zero values of the deformations of all elastic elements $^{[4]}$. To compose the equations of the movement use the Lagrange equations of the type II.

$\frac{\mathrm{d}}{\mathrm{dt}}\left(\frac{\partial \mathrm{T}}{\partial \dot{\mathrm{q}}_{\mathrm{i}}}\right)-\frac{\partial \mathrm{T}}{\partial \mathrm{q}_{\mathrm{i}}}+\frac{\partial \mathrm{N}}{\partial \mathrm{q}_{\mathrm{i}}}=\mathrm{Q}_{\mathrm{i}}$

Where:

$\mathrm{q}_{\mathrm{i}}$ - Generalized coordinates,

$\mathrm{Q}_{\mathrm{i}}$-Generalized force ${ }^{[4]}$.

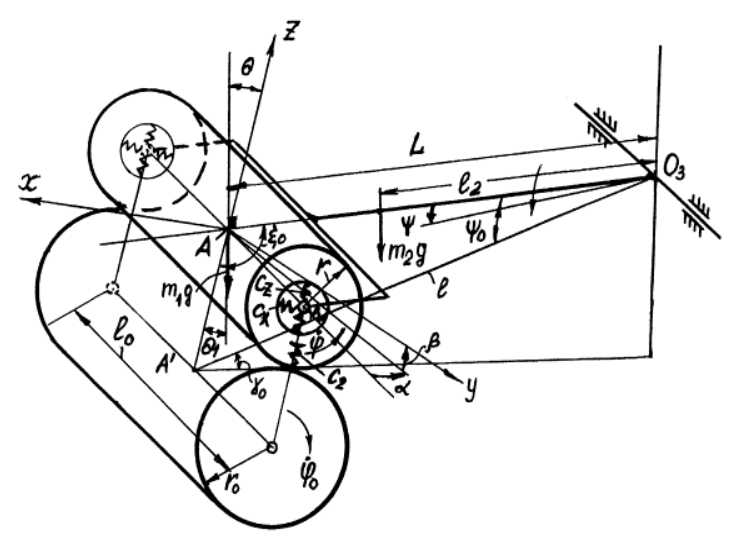

Fig. 1: Frictional Winding Mechanism Scheme 
Kinetic $\mathrm{T}$ and potential $\mathrm{N}$ energy of the FWM are defined by the equalities:

$$
\begin{aligned}
& \mathrm{T}=\frac{1}{2}\left[\mathrm{~m}_{1}\left(\dot{\mathrm{X}}^{2}+\dot{\mathrm{Z}}^{2}\right)+\mathrm{J}_{\mathrm{Y}}(\dot{\phi}-\dot{\beta} \alpha)^{2}+\right. \\
& \left.+\mathrm{J}_{\mathrm{X}}\left(\dot{\beta}^{2}+\dot{\alpha}^{2}\right)+\mathrm{J}_{\mathrm{o} 3} \dot{\Psi}^{2}\right] \\
& \mathrm{N}=\frac{1}{2} \mathrm{c} \int_{-\frac{1_{\mathrm{o}}}{2}}^{\frac{1_{\mathrm{o}}}{2}}(\beta \mathrm{y}+\mathrm{Z})^{2} \mathrm{dy}+\frac{1}{2} \mathrm{c}_{\mathrm{Z}}\left[\frac{1_{\mathrm{o}}}{2} \beta+\mathrm{Z}+\mathrm{L} \sin \xi_{\mathrm{o}} \cdot \Psi\right]+ \\
& +\frac{1}{2} \mathrm{c}_{\mathrm{Z}}\left[-\frac{1_{\mathrm{o}}}{2} \beta+\mathrm{Z}+\mathrm{L} \sin \xi_{\mathrm{o}} \cdot \Psi\right]^{2}+ \\
& +\frac{1}{2} \mathrm{c}_{\mathrm{X}}\left[-\frac{1_{\mathrm{o}}}{2} \alpha+\mathrm{X}-\mathrm{L} \cos \xi_{\mathrm{o}} \cdot \Psi\right]^{2}+ \\
& +\frac{1}{2} \mathrm{c}_{\mathrm{X}}\left[\frac{1_{\mathrm{o}}}{2} \alpha+\mathrm{X}-1 \cos \xi_{\mathrm{o}} \cdot \Psi\right]^{2}
\end{aligned}
$$

In the Eq. 2 and Eq. 3 there are:

$\mathrm{m}_{1}$-Mass of the package,

$\mathrm{J}_{\mathrm{Y}}$-Axial mass moment of inertia of the package,

$\mathrm{J}_{\mathrm{X}}$-Equatorial mass moment of inertia of the package,

$\mathbf{J}_{03}$-Mass moment of inertia of the pendulum lever and the package relative axis $\mathrm{O}_{3}$,

$c_{\mathrm{x}}$ And $\mathrm{c}_{\mathrm{z}}$ - linear stiffnesses of the package support along two perpendicular directions,

$c_{2}$-Continuous stiffness of the package body.

Moments of the members gravity forces, moments of the friction forces and moments due to statical and dynamical mis balances of the package mass are taken into account among outer forces applied to the FWM $^{[5]}$. Applying Eq. 2 and Eq. 3 in Eq. 1 after reduction get the following system of the equations of the movement:

$$
\left.\begin{array}{l}
\mathrm{m}_{1} \ddot{\mathrm{X}}+\mathrm{b}_{\mathrm{X}} \dot{\mathrm{X}}+2 \mathrm{c}_{\mathrm{X}} \mathrm{X}-2 \mathrm{c}_{\mathrm{X}} \mathrm{L} \cos \xi_{\mathrm{o}} \cdot \Psi \\
=-\mathrm{m}_{1} \mathrm{~g} \cdot \sin \theta_{1}+\mathrm{F}_{\mathrm{f}}+\mathrm{dm} \cdot \mathrm{e} \cdot \dot{\varphi}^{2}[\cos \varphi+\cos (\varphi+\varepsilon)], \\
\mathrm{m}_{1} \ddot{\mathrm{Z}}+\mathrm{b}_{\mathrm{Z}} \dot{\mathrm{Z}}+\left(2 \mathrm{c}_{\mathrm{Z}}+\mathrm{c}_{2} \ell_{\mathrm{o}}\right) \mathrm{Z}+2 \mathrm{c}_{\mathrm{Z}} \mathrm{L} \sin \xi_{\mathrm{o}} \cdot \Psi \\
=-\mathrm{m}_{1} \mathrm{~g} \cdot \cos \theta_{1}+\mathrm{dm} \cdot \mathrm{e} \cdot \dot{\varphi}^{2}[\sin \varphi+\sin (\varphi+\varepsilon)], \\
\mathrm{J}_{03} \ddot{\Psi}+\mathrm{b}_{\Psi} \dot{\Psi}+2 \mathrm{~L}^{2}\left(\mathrm{c}_{\mathrm{Z}} \sin ^{2} \xi_{\mathrm{o}}+\mathrm{c}_{\mathrm{X}} \cos ^{2} \xi_{\mathrm{o}}\right) \Psi \\
+2 \mathrm{c}_{\mathrm{Z}} \mathrm{L} \sin \xi_{\mathrm{o}} \cdot \mathrm{Z}-2 \mathrm{c}_{\mathrm{X}} \mathrm{L} \cos \xi_{\mathrm{o}} \cdot \mathrm{X}=\mathrm{m}_{2} \mathrm{~g} \ell_{2} \cos \theta_{1}+\mathrm{M}_{\mathrm{b}} \\
\mathrm{J}_{\mathrm{X}} \ddot{\alpha}+\mathrm{b}_{\alpha} \dot{\alpha}+\mathrm{J}_{\mathrm{Y}} \dot{\varphi} \dot{\beta}+\frac{\ell_{\mathrm{o}}^{2}}{2} \mathrm{c}_{\mathrm{X}} \alpha \\
=\frac{\ell_{\mathrm{o}}}{2} \mathrm{dm} \cdot \mathrm{e} \cdot \dot{\varphi}^{2}[\cos \varphi-\cos (\varphi+\varepsilon)]+\mathrm{M}_{\mathrm{a}}, \\
\mathrm{J}_{\mathrm{Y}} \ddot{\varphi}=\mathrm{M}_{\mathrm{f}}-\mathrm{M}_{\mathrm{r}}
\end{array}\right\}
$$

In these equations, the analytically found values of $F_{f}, M_{a}$ and $M_{f}$ will depend upon the character of the contact of the package and driving drum. Note also that the moment $\mathrm{M}_{\mathrm{b}}$ due to balancing members and the moment $\mathrm{M}_{\mathrm{r}}$ of resistance to package rotation are considered to be constants for fixed nominal diameter of the package. Statical and dynamical mis balance of the package mass are taken into account in the Eq. 4 by means of the allocation at the flat faces of the package of the small masses deem whose vectors of inertia forces from the angle $\varepsilon$ between themselves.

Later only those modes of FWM operation will be considered when the package touches were driving drum by along its length. For other modes of operation either owing to jumping up of the package on the driving drum or due to not the all length of their contact we shall not only the fact of existence such modes.

For the above taken generalized coordinates for the contact with the package and frictional driving drum along the length will be achieved when the deformation of both left and right flat faces of the package corresponds with the below given where inequalities:

$$
\mathrm{z}+\beta \frac{\mathrm{l}_{0}}{2} \leq 0, \quad \mathrm{z}-\beta \frac{\mathrm{l}_{0}}{2} \leq 0 .
$$

When conditions (5) are observed, three modes could be realized. We shall consider that to the mode I correspond the conditions under which the peripheral speeds of the points of contact with the package and driving drum in all the cross sections are less than the speeds of the same points belonging to the driving drum:

$$
\left.\begin{array}{c}
\left(\mathrm{r}+\mathrm{z}+\beta \frac{\mathrm{l}_{0}}{2}\right) \dot{\phi}+\frac{1_{0}}{2} \dot{\alpha}<\mathrm{r}_{0} \dot{\phi}_{0}, \\
\left(\mathrm{r}+\mathrm{z}-\beta \frac{\mathrm{l}_{0}}{2}\right) \dot{\phi}+\frac{1_{0}}{2} \dot{\alpha}<\mathrm{r}_{0} \dot{\phi} .
\end{array}\right\}
$$

Apparently the mode of running up of the package corresponds to these conditions. For this mode have:

$$
\begin{aligned}
& F_{f}=f c_{2} \int_{-\frac{l_{0}}{2}}^{\frac{l_{0}}{2}}(z+\beta y) d y, \\
& M_{\alpha}=-f_{2} \int_{-\frac{l_{0}}{2}}^{\frac{l_{0}}{2}} y(z+\beta y) d y, \\
& M_{f}=-f_{2} \int_{-\frac{I_{0}}{2}}^{\frac{l_{0}}{2}} r(y)(z+\beta y) d y,
\end{aligned}
$$

Where:

$$
r(y)=r+z+\beta y,
$$

$r(y)$ are the values of deformed radii of the package along its axis. 


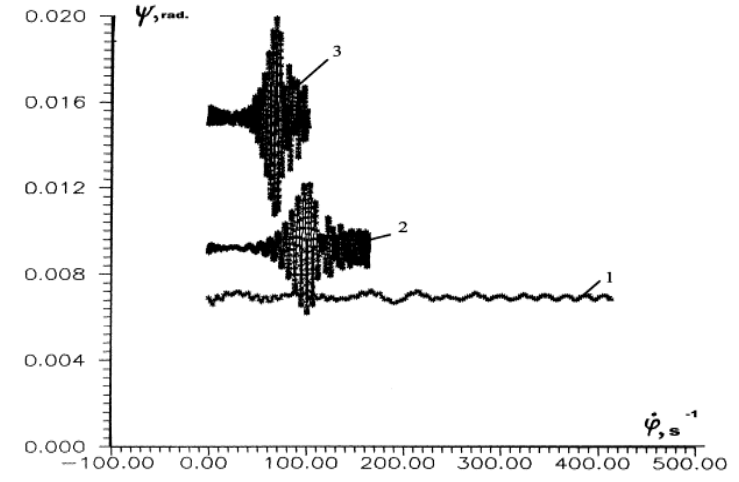

Fig. 2: Vibrations of the Lever $\mathrm{AO}_{3}$ during Package Running up

In the contrary case (mode II) when the speeds of the points of the package are higher than the speeds of the points of the driving drum there will take place a braking of the package and to find the values of $\mathrm{F}_{\mathrm{f}}, \mathrm{M}_{\mathrm{a}}$ and $\mathrm{M}_{\mathrm{f}}$ are enough to change in equalities (7) the signs for the opposite ones. Herewith the following conditions must be kept:

$$
\left.\begin{array}{c}
\left(\mathrm{r}+\mathrm{z}+\beta \frac{1_{0}}{2}\right) \dot{\phi}+\frac{1_{0}}{2} \dot{\alpha}>\mathrm{r}_{0} \dot{\phi}_{0}, \\
\left(\mathrm{r}+\mathrm{z}-\beta \frac{1_{0}}{2}\right) \dot{\phi}+\frac{1_{0}}{2} \dot{\alpha}>\mathrm{r}_{0} \dot{\phi} .
\end{array}\right\}
$$

If the conditions (6) and (8) are not observed then the rotation of the package becomes steady run or closed to it (mode III) and at the length of the package always there could be found a cross section at which the peripheral speeds of contact points of the package and driving drum are of the same value. The radius of the package at this cross section is called as effective one while a coordinate of relevant cross section is defined by the equation:

$\mathrm{y}_{\mathrm{E}}=\frac{\mathrm{r}_{0} \dot{\varphi}_{0}-(\mathrm{r}+\mathrm{z}) \dot{\varphi}}{\beta \dot{\varphi}+\dot{\alpha}}$

If in the equality (9) $\beta \dot{\varphi}+\dot{\alpha}=0$ then it should be admitted that $\mathrm{y}_{\mathrm{E}}=0$.

For the mode III the values of the frictional efforts are found from the equalities:

$$
\begin{aligned}
& F_{f}= \pm f c_{2}\left[\int_{-\frac{I_{0}}{2}}^{y_{E}}(z+\beta y) d y-\int_{y_{E}}^{\frac{1_{0}}{2}}(z+\beta y) d y\right], \\
& M_{\alpha}= \pm f c_{2}\left[-\int_{-\frac{I_{0}}{2}}^{y_{E}} y(z+\beta y) d y+\int_{y_{E}}^{\frac{1_{0}}{2}} y(z+\beta y) d y\right]
\end{aligned}
$$

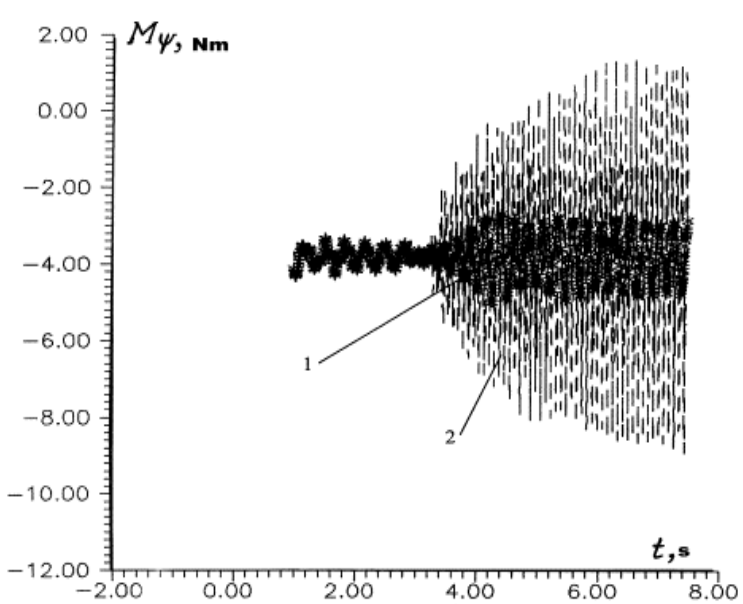

Fig. 3: Influence of Elasticity of Supports over Values of Elastic Moments Applied to the Lever $\mathrm{AO}_{3}$

$M_{f}= \pm f c_{2}\left[-\int_{-\frac{1_{0}}{2}}^{y_{E}} r(y)(z+\beta y) d y+\int_{y_{E}}^{\frac{l_{0}}{2}} r(y)(z+\beta y) d y\right]$

where, + is taken when $\beta \geq 0$.

So far, as the system of Eq. (4) is nonlinear then to solve it there is necessary to use numerical methods of

Solving of differential equations. In the case under consideration the method based on the presentation of the solution as the Tailor series is used. For its realization there was developed the program in algorithmic language $\mathrm{C}++$. On the base of this program within the frames of the assumptions done, the numerical modeling was achieved in the real winding

Up process both for study and for no steady modes of FWM run.

Figure 2 presents an example of the graph of the vibrations of the lever $\mathrm{AO}_{3}$ for package running up. Here the curves 1, 2 and 3 correspond to the start of winding $(\mathrm{r}=0,04 \mathrm{~m})$, to the middle $(\mathrm{r}=0,10 \mathrm{~m})$ and to the end $(\mathrm{r}=0,16 \mathrm{~m})$. Presented graphs demonstrate that for small diameters of the package the ones of a resonance are higher than the frequency of steady rotation of the package whilst for mid and bigger diameters the package goes through the resonance zones and the amplitudes of the lower vibrations in these zones increase sharply. Firstly such a character on the package running up process is connected with the increase of its mass and moments of inertia due to the increase of the package diameter. At the same time it is necessary to take into account that all other parameters of FWM, mainly stiffness of the pack and supports, affect the character of the running up process. So the Fig. 3 presents the curves of the moments applied from the supports side to the lever $\mathrm{AO}_{3}$ over package running up $(r=0,10)$ for cases of elastic 1 and hard supports 2 . Diminution of the loading of elastic supports in this 
case analogically to the phenomenon of self-centering of rotors is explained by the running of FWM in overresonance zone ${ }^{[4]}$.

\section{CONCLUSION}

The use of the developed algorithms and software for realization of numerous computations confirmed the reliability of the offered mathematical model of the FWM.

The FWM is recommended for searching of optimal structural and physical parameters for developing a new and updating the existing FWMs.

\section{REFERENCES}

1. Alnawafleh, M.A., 2001. Determination of the conical bobbin effective radius in frictional winding mechanism. Proceeding of the $15^{\text {th }}$ European Simulation Multi Conference, Society for Computer Simulation International, Praque, pp: 497-500.
2. Alnawafleh, M.A., 2001. Oscillation analysis in winding mechanisms actuated by rotating frictional drum. Proceeding of the 13th European Simulation Symposium, Simulation in Industry. Society for Computer Simulation International, Marseille, France, pp: 20-24.

3. Galchook, T.A., 1999. Analysis of modes of the run of high speed frictional take up motions with pendulum suspension. Unpublished Ph.D. Thesis, Saint-Petersburg.

4. Loytsyansky, L.G. and Lourie, A.I., 1983. Course of Theoretical Mechanics. Dynamics, Nauka Publishers, Moscow, 2: 640.

5. Hibbeler, R.C., 1997. Engineering Mechanics Statics and Dynamics. SI Edn. Simon and Schuster (Asia) Plt. Ltd. Singapore. 